\title{
In memoriam: la escucha en la poética y ética de Roberto Burgos Cantor
}

Fecha de recepción: 3 de septiembre de 2018

Fecha de aprobación: 15 de enero de 2019

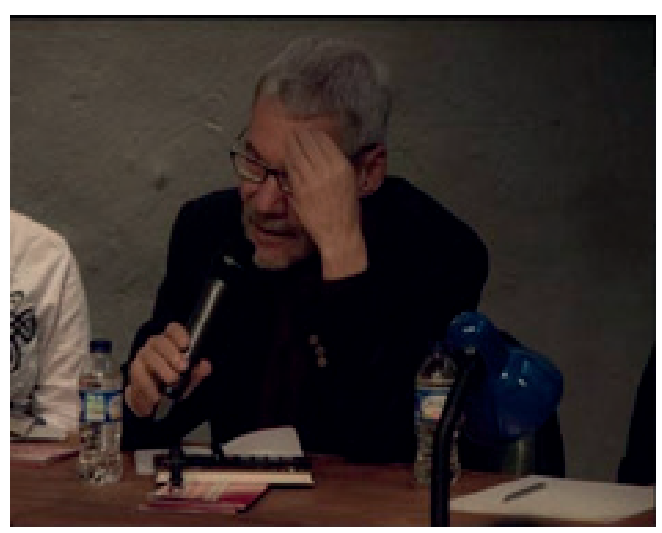

\section{Preludio}

Este texto es un extracto de que fuera escrito para ser leído ante la audiencia que, el 12 de febrero de 2019, se reunió en la sede de la Asociación de Egresados de la Universidad de los Andes -Uniandinos- para hacerle homenaje a la vida literaria de Roberto Burgos Cantor, quien falleció en Bogotá el 16 de octubre de 2018, dejando tras sí siete novelas: El patio de los vientos perdidos (1984, 2001, 2013, 2014), El vuelo de la paloma (1992), Pavana del ángel (1995, 2014), La ceiba de la memoria (2007, 2009) -ganadora del Premio de Narrativa Casa de las Américas 2009 y finalista del Premio Rómulo Gallegos 2010-, Ese silencio (2010), El médico del emperador y su hermano (2016), y Ver lo que veo (2017) -ganadora del Premio Nacional de Novela 2018-; ocho libros de cuentos: Lo Amador (1980, 2001, 2012), Lo Amador y otros cuentos (1986), De gozos y desvelos (1987), Quiero es cantar (1998), Juegos de niños (1999), Una siempre es la misma (2009), El secreto de Alicia (2013) y Orillas (2019, póstuma); y un libro de testimonio de época: Señas particulares $(2001,2011)$.

Citar: Urrea, A. (enero-junio de 2019). In Memoriam: la escucha en la poética y ética de Roberto Burgos Cantor. La Palabra, (34), 19-25. (do) https://doi. org/10.19053/01218530.n34.2019.9510

\section{Adriana Urrea Profesora}

Facultad de Filosofía, Pontificia Universidad Javeriana; y Maestría Interdisciplinar en Teatro y Artes Vivas, Universidad Nacional de Colombia 
Aquella noche, antes de iniciar la lectura, le propuse a los cuerpos allí presentes que escucháramos el Aria de la Bachiana 5 de Heitor Villa-Lobos (https:// www.youtube.com/watch?v=maQ8t8mJkTM, minutos 0:463:55).

En esta ocasión, que la editora del presente número de la revista La Palabra, Juliana Borrero, me ha pedido un texto en homenaje a Roberto Burgos Cantor, sugiero a la o el lector que antes de recorrer las líneas que llegan, escuche el Aria de cualquiera de las Variaciones Goldberg interpretadas por Glenn Gould en 1955 (https://youtu.be/QHHtwrqsrLE), cuando apenas llegaba a los veintidós años, en una versión no remasterizada aún y en la que se escuchan los siseos de la tecnología de entonces, el longplay.

\section{Aria $^{1}$}

Durante casi veinte años, Roberto tuvo una columna en el diario El Universal de Cartagena de Indias, de Baúl de mago. En la que títuló "Poderes nuevos", escrita al regresar de Bucaramanga, en donde se le había hecho un homenaje el 29 de agosto de 2018 con ocasión de haberle sido otorgado el Premio Nacional de Novela 2018 el 26 de julio por Ver lo que veo, su última novela, veía con espe- ranza la fuerza de porvenir que abría el movimiento estudiantil de estos días. Reproduzco acá un aparte de la misma:

Si uno liberara el presente, trabado o vertiginoso, de Colombia, podría encontrar conjeturas que no significan mucho, están allí como un signo, una reiteración, un pasado que no cesa.

Parecería que siempre se quiso, después de guerras, tener una sociedad dividida por mitades: rojos y azules, indiferentes y devotos, secularizar o bendecir. Se crearon estructuras políticas que preservaran un país gobernado así. La paridad, la alternación. Cuando las mitades se fragmentaban en su interior, se aplicaba la milimetría. Nunca se pensó en la posibilidad de que las mitades se unieran, se fundieran.

$$
\text { [...] }
$$

La persistencia de las mitades, se puede analizar en dos acontecimientos.

El plebiscito sobre la paz. Escrito así parece una simpleza. La verdad es que se trataba de un logro arduo, de años de aprender a conversar, de sentir que convencer es un arte, una victoria de la razón, un cambio de la sensibilidad. Encontrar el suelo común.

\section{$[\ldots]$}

Sin embargo quedaron en el plebiscito dos mitades. Y lo admirable es que una de ellas correspondía a los jóvenes, a los incrédulos por asco. Y esa presencia, de quienes se alejaron del fracaso de su padres y abuelos, es la que hoy carga de poder la esperanza.

Volvió a ocurrir con el referendo contra la corrupción. Las mitades están cambiando.

Lo demás, Baena Sosa dixit: ¡sale por chatarra! (Burgos Cantor, 1 de septiembre de 2018).

Este movimiento era vital para un hombre que, en Señas particulares (Burgos Cantor, 2001), había escrito:

Para mis compañeros de generación, por temporalidad o por afinidad de deseo, el tiempo en que vivimos sigue siendo hasta hoy un problema. Otros lo denominan catástrofe. ¿En cuál momento la recibimos? Tristeza o reto, herencia forzada o rechazo. Largo forcejeo con una realidad inconmovible que no satisface a nadie y derrota los sueños.

$$
[\ldots]
$$

Al final de esta década de prodigio el mundo otra vez

\footnotetext{
1 He titulado este aparte Aria, pues constituye, como las arias en la música, la primera parte de un tema que desarrollará, a modo de variaciones, la poética de la escucha de Roberto Burgos Cantor.
} 
era viejo. Una regresión autoritaria, implacable y laboriosa, con un poder intimidatorio y destructivo que no hacía ruido, avanzaba como una aplanadora y uniformaba todo. (pp. 9, 42).

¿Cuál sería la opción entonces?: Escribir para no morir y para mantener una resistencia ante el fracaso de la transformación del mundo. La urgencia de la vida está en cada letra que Burgos Cantor escribió, y por ella no morirá: queda su obra que hoy nos reúne.

En el preámbulo de Señas particulares, afirmaba la necesidad de esta resistencia:

Las páginas que siguen $[\ldots]$ pretenden $[\ldots][\mathrm{m}]$ ostrar que si algo emparenta a los escritores de mi generación es hacer del estilo un dominio de la crítica, corregir las versiones oficiales de lo histórico, denunciar el pasado, subvertir el orden, mostrar las ideas, proponer otro pensamiento cuando se tropiece con las certezas. (Burgos Cantor, 2001, p. 11).

En la escritura encontró la manera de vivir: escribo para no morir repitió de muchas maneras y repito acá. Era una resistencia contra la muerte en vida, como lo hace todo gran artista. Impuso siempre el conato de vida a la tentación de la muerte. Este deseo irrefrenable por producir belleza y vida, estaba acompañado de una escucha afinada. Como si auscultara el mundo y los seres que los habitan: "El arte revela. La vida dice" (Burgos Cantor, 2001, p. 32).

La capacidad de escucha de Roberto Burgos Cantor de su tiempo, era infinita: escuchaba la realidad con sus cacofonías, a los profesores y alumnos que lideraba con la fuerza de su creación y la urgencia siempre de construir una comunidad por efímera que fuera.

Como Director de Posgrados del Programa de Creación Literaria de la Universidad Central, inventó un Seminario Intersemestral de Posgrados que reunía a profesores de pregrado para indagar sobre lo que podría ofrecer a quien quiere escribir Literatura. Esos seminarios iban acompañados de una publicación previa con los textos, que sería motivo de reflexión y que provenían de la atenta escucha de sus profesores.

Como profesor, su escucha a la potencia poética de lo que llamaba escritores cachorros, era de un respeto casi reverencial, y con su memoria prodigiosa lograba rescatar del olvido de los propios estudiantes los senderos que estos habían emprendido.

Roberto quería subvertir como todo lo establecido que anquilosara la vida; ir contra aquello que en las escuelas se siguen repitiendo: "la pared y la mu- ralla son el papel de la canalla" (Burgos Cantor, 2001a, p. 85). $\mathrm{Su}$ escucha permitía reconocer en las creaciones de los escritores cachorros lo que clamaba Antonin Artaud a Jacques Rivère, el editor de la Nouvelle Revue Française: "las potentes bellezas" en una creación defectuosa. Y coincidiría con este cuando afirmaba que un poema puede ser perfecto, pero carecer de resonancia interior, de vida (Artaud, [1924] 2007, p. 61).

Esta voluntad de escucha a las múltiples voces, y a las bellezas y atrocidades del mundo, aparece de manera palmaria en uno de mis cuentos favoritos "Si tu voz, un invierno", que hace parte de su libro Quiero es cantar. Relata la historia de un hombre que reside en Panamá y una madrugada contesta una llamada telefónica que parecer ser equivocada. Al otro lado de la línea, una mujer habla en una lengua que parece ser oriental. Ante la incomunicación de idiomas, él cuelga, pero quien llama insiste una y otra vez. El hombre, a su vez, responde una y otra vez, y termina estableciendo una relación con esa voz:

La voz se precipita hacia su callarse y queda a medio tono con sus modulaciones. Dice una y otra vez un vocablo que me suena a nombre. No es el mío. Lo dice o lo canta o lo añora o lo llama con una obstinada recurrencia que lo pone en el oído [...] 
Voy a contestar con la esperanza de que la voz de palabras ininteligibles esté ahí. Alimento de mi martirio. [...] Antes de poner el aparato en la oreja me alcanza el tono con su timbre seguro de ave escondida. Repite su canto inmemorial y lo impone a las heridas del tiempo. Lo escucho un instante y de repente se silencia en lo alto de una voz donde ya no es posible una escala ni una nota más sin tornarse en aullido [...] Espero. No hay expectativa. Ni tensión. [...].

Me apoyo en la pared y despacio flexiono las piernas hasta quedar en cuclillas [...].

Es innecesario hablar. La voz sabe que estoy aquí y no le interesa oírme ni me va a responder. Existe para que yo la escuche y lo hago. Me entrego a su capricho o a su exigencia o a su necesidad.

El miedo se fue y un estado de indefensión inocente me convierte en el caracol guardador de estos sonidos y los protege de los huracanes desordenados que rondan el mar [...].

Las peripecias de la voz desorbitan el encantamiento. Nada es ya posible sin su presencia. Un destello tenue de alarma me impulsa a colgar el teléfono. Un intento de huir de lo que se quiere. Extraño gesto.
Cuando me detiene la extrañeza, suena el teléfono.

Con la fuerza del deseo que desconozco, del reclamo al cual me uno, del secreto que trae a las vigilias las palabras del sueño sin confundirlas, la voz vuelve otra vez a conquistar el espacio y la siento ascender y ascender sin escalas, en el delirio de la subida $\sin$ final $[\ldots]$

Hace cuánto que estoy aquí, necesitado de la voz. Me acompaña y me llama y me canta. Hace cuánto. No importa. No abro nunca la puerta [...]. Jamás se irá la voz y yo aquí entre los caminos de las arañas y las hormigas muertas. Llueve. La voz es como una pena inacabable. Llueve. (Burgos Cantor, 1998, pp. 34, 36-40).

La escucha de Roberto era así. Escuchaba lo abominable y lo convertía en belleza como lo hizo en marzo del año pasado, cuando en Experimenta/Sur ${ }^{22}$ del 2017 fue invitado, junto a psicoanalistas, juristas, antropólogos y artistas de diferentes procedencias, a escuchar el testimonio de una víctima mujer de este conflicto armado que no parece querer abandonarnos.

Produjo in vivo, in situ un cuento: fue su respuesta inminente ante el horror que la audiencia había escuchado. No era posible analizarlo: solo le restaba transponerlo a la ficción, buscarle una forma nueva. Así como Otilia, la mujer de Ver lo que veo, les dice a sus vecinas:

Cuando vayamos al cine miremos a las artistas y nos prestarán ideas para los peinados, las sombras de los ojos, el color y la línea de los labios, la remolacha tenue y marcada de los pómulos. No para imitar. ¿Ustedes creen que hubiéramos soportado vivir en este barrio con la imitación de lo ajeno? (Burgos Cantor, 2018, p. ).

Escuchaba la lengua suelta de las calles, la lengua plebeya como diría Flaubert, a quien tanto citaba, o popular como diría Pasolini, a quien tanto leía y veía. Escuchaba la lengua de los juglares como Alejo Durán y Pedro García:

Los años y sus acomodos me dejaron ver que no bastaban ya los versos de Neruda o de Gaitán Durán o de Cote, para atreverse a aludir a alguno de los sobresaltos del corazón por ese entonces sin expresión propia.

Entonces aparecieron los cantos vallenatos y su poder eficiente para despedirse de una enamorada, para mitigar las nubes oscuras de un guayabo temprano, para dolerse de una ausencia. (Burgos Cantor, 2007).

Programa de reflexión y creación liderado por Mapa Teatro y el Goethe-Institut de Bogotá. 
Escuchaba poesía y músicas de las más diversas procedencias, como se hace evidente a lo largo de su obra. De ahí que, fuese imposible empezar a hablar de la misma y de su escucha sin proponer una pieza musical.

Hubiera podido yo proponer que escucharan a U2 o a Pedro García, una champeta, un son, al Septeto Nacional de Cuba o un bolero: jamás un canon lo constriñó. En el cuestionario que "Lecturas dominicales" de El Tiempo le propuso tras haber ganado el Premio Nacional de Novela le preguntaba, entre otras cosas, le preguntaba si tenía alguna manía al escribir, la respuesta de Roberto fue: "Siempre la misma música al fondo. La escojo al empezar. Ayuda a aislarme" (Burgos Cantor, 2018a).

Como Mallarmé encontró en la música la resonancia que existía entre los procedimientos de la música y de las palabras, $\mathrm{y}$ por ello su preocupación por que la poesía tuviera un lugar preponderante en la formación de los escritores de ficción. Era "un elemento renovador en las diversas búsquedas creativas" más "allá de las mecánicas normativas del género" (Burgos Cantor, 2018b, p. 22). Tenía la certeza, como Aristóteles lo había intuido, de que la poesía es el ámbito de lo que puede ser y en eso se diferencia de la historia, que se obstina en lo que es.
Leyendo me he preguntado si Rimbaud sería acaso un curso inexcusable [...]. Tal vez, a la manera de Bonnefoy, cuando muestra la necesidad de este poeta y la indispensable reflexión que implica. No sé qué tanto ocurre con Hölderlin en el momento en que los dioses, o Dios, abandona a los seres y al mundo. (Burgos Cantor, 2018b, p. 22).

Es esta escucha sin igual, la que le obliga a forjar el lenguaje, a esculpir su tiempo y sus ritmos, resonancias y disonancias. El coro que hoy está en duelo extrañará esta escucha excepcional. Decía Roberto en Señas particulares, que "El escritor es un cómplice del riesgo" (Burgos Cantor, 2001, p. 88). Uno de ellos era una escucha como la del hombre de "Si una voz un invierno".

Tenía la obstinación y la paciencia para reinventarse en su escritura, como algunos de sus personajes: el constructor de jaulas, de Juegos de niños; el ebanista, de Ese silencio o de Ver lo que veo; o también el boxeador, de Ver lo que veo, que inventa un nuevo oficio para el barrio, y que, con su triunfo, da lugar a una celebración en un barrio a cuyos pobladores la ciudad amurallada, histórica, de Cartagena de Indias, había invisibilizado.

Este festejo da lugar a que los fundadores de ese barrio de desplazados, Otilia y el ebanista, hablen. Se pregunta la mujer: “¿Qué será lo que hace hablar a la gente?" (Burgos Cantor, 2017, p. 115). Le responde el ebanista:

Hace falta hablar. El miedo y la rabia nos robaron las palabras. Creo que a la gente la alegría la impulsa a hablar, la proximidad de la felicidad. La tristeza silencia. No hablamos y la cabeza se llena de ideas, recuerdos que se deforman, queda vuelta un sonajero de piedras, con tantos días callado es difícil sacarlas. Algunas se pudren. Podrido silencio de la vida. (Burgos Cantor, 2017, p. 116).

Cuando la gente finalmente habla, es preciso escucharla, consideraba Burgos Cantor: era la condición sine qua non para hacer surgir día a día la posibilidad de estar juntos, tema recurrente en la obra de Burgos Cantor que, alguna vez, en un escrito jurídico, acuñó la siguiente fórmula S.O.S.: Soledad o Solidaridad.

En esa conversación entre Otilia y el ebanista, aparecen preguntas hondas que se hacen quienes han sido expulsados, desterrados, desplazados o exilados, indagan por el sentido de construir ese barrio en el que se inventan a diario los habitantes para no estar solos (Burgos Cantor, 2017, p. 116). 
Otilia no tiene dudas:

Hay que imaginar. No es imposible. Imaginar con rabia. Imaginar con alegría. Se acuerdan de la mujer, la artista que trabaja en las películas de criminales y de investigadores particulares que beben whisky para resistir la maldad humana, el fracaso de las virtudes. [...]. Los que dirigen a los artistas, los que maquillan, las modistas, les agregan una belleza, un carácter, el esplendor del mal. Parece mentira, ¿verdad?, que la perversidad tenga belleza. (Burgos Cantor, 2017, pp. 28-29).
La obra de Roberto Burgos Cantor ha imaginado con rabia y con alegría, es producto de una escucha siempre atenta a quienes hablan o quieren hacerlo, a las manifestaciones de lavida y sus amenazas. Con ella se impuso a la catástrofe, a ese retorno sin fin de la injusticia y la pérdida de libertad.
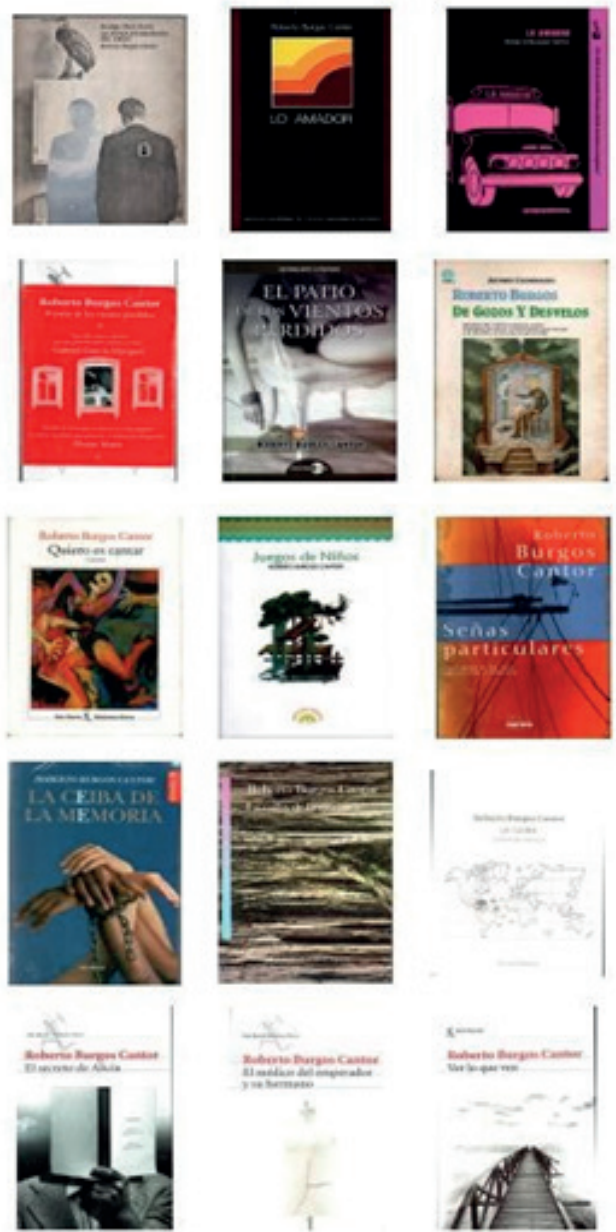

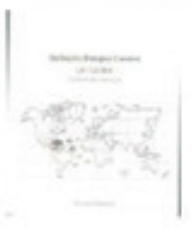

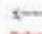
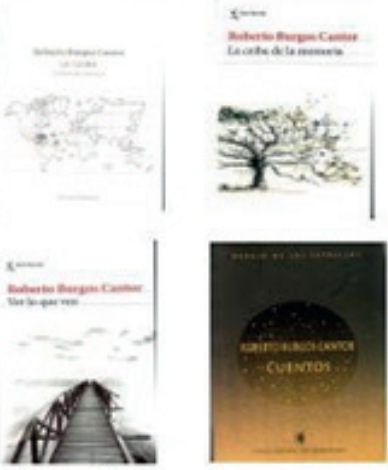
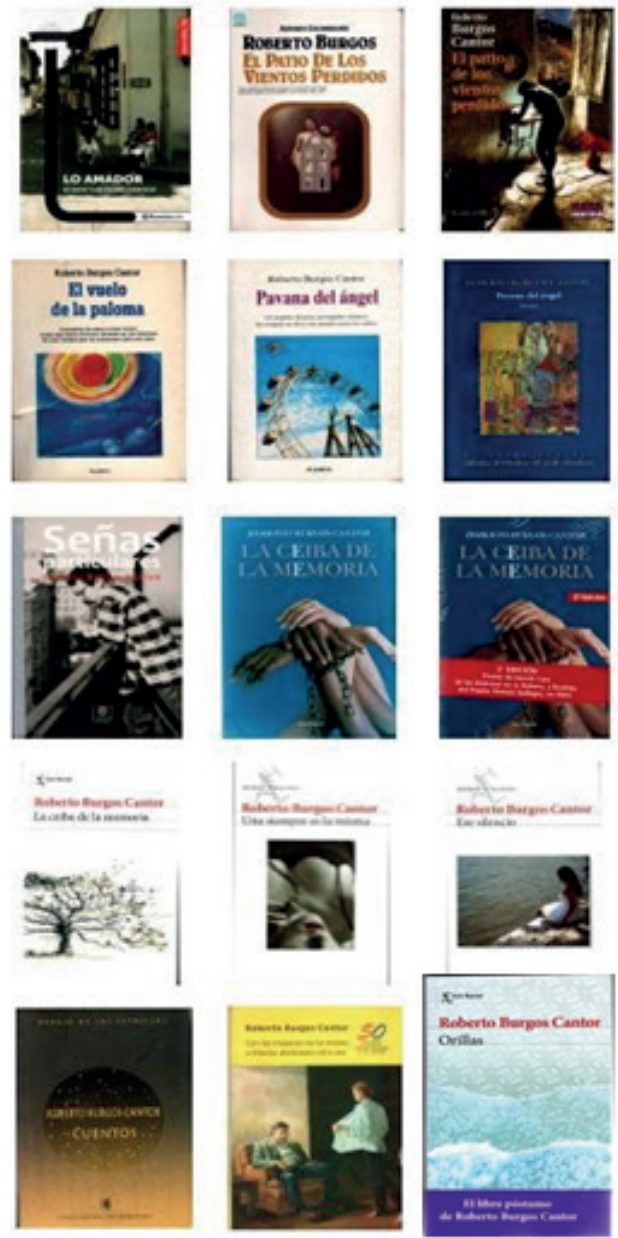


\section{Referencias}

Artaud, A. ([1924] 2007). Cartas a Jacques Rivière. En Textos escogidos (pp. 55-82).

Buenos Aires: Cántaro.

Burgos Cantor, R. (1998). Quiero es cantar. Bogotá: Seix Barral. Burgos Cantor, R. (2001). Señas particulares. Bogotá: Editorial Norma.

Burgos Cantor, R. (2001a). Lo Amador. Bogotá: Editorial Norma.

Burgos Cantor, R. (2007, abril). Baúl de mago: "Canto y rezo". En El Universal. Cartagena de Indias.

Burgos Cantor, R. (2010, 18 de septiembre). Baúl de mago: "Destinos memorables". En El Universal. Cartagena de Indias.

Burgos Cantor, R. (2017). Ver lo que veo. Bogotá: Seix Barral.

Burgos Cantor, R. (2018, 1 de septiembre). Baúl de mago: "Poderes nuevos". En El Universal. Cartagena de Indias.

Burgos Cantor, R. (2018a, 12 de agosto). Cuestionario. El Tiempo: "Lecturas dominicales".

Burgos Cantor, R. (2018b). Presentación. Horizonte y sentido de un seminario. Experiencias y reflexiones (pp. 11-14). Bogotá: Departamento de Creación Literaria- Universidad Central. 